\title{
Ordem e Poder na Economia Política Global: A Contribuição Neogramsciana*
}

\section{Leonardo Ramos**}

\section{Introdução}

Em 19 de março de 1927, pouco tempo após ser preso, Gramsci expõe para a cunhada, Tatiana Schucht, seus planos de trabalho para seu período no cárcere: "Estou atormentado por esta ideia: de que é preciso fazer algo für ewig [...]. Em suma, segundo um plano preestabelecido, gostaria de me ocupar intensa e sistematicamente de alguns temas que me absorvessem e centralizassem minha vida interior" (GRAMSCI, 2005, p. 128).

\footnotetext{
* Artigo recebido em 21 de junho de 2011 e aprovado para publicação em 19 de junho de 2012.

** Doutor em Relações Internacionais pela Pontifícia Universidade Católica do Rio de Janeiro (PUC-Rio), professor adjunto do Departamento de Relações Internacionais da Pontifícia Universidade Católica de Minas Gerais (PUC-Minas) e professor do Centro Universitário de Belo Horizonte (Uni-BH). E-mail: lcsramos@ pucminas.br.
}

CONTEXTO INTERNACIONAL Rio de Janeiro, vol. 34, noำ 1, janeiro/junho 2012, p. 113-150. 
Tal objetivo começou a ser perseguido de maneira mais sistemática a partir do início de 1929, conforme carta de Gramsci de 25 de março (GRAMSCI, 2005, p. 328-331). Embora não haja uma interpretação consensual da obra de Gramsci, é possível perceber certa continuidade nas preocupações e temas que perpassam seu raciocínio desde os artigos conjunturais do Ordine Nuovo até as notas dos Cadernos do cárcere. Ou seja, se de uma perspectiva meramente formal "os $\mathrm{Ca}$ dernos conservam um caráter fortemente fragmentário [...], (d)o ponto de vista do conteúdo, porém, a preocupação sistemática é evidente" (COUTINHO, 2007, p. 79). Os Cadernos podem, assim, ser vistos como a maturação de um pensamento que vinha desde 1921, com destaque para a carta enviada ao Comitê Central do Partido Comunista (COUTINHO, 1981, p. 170-175) e o ensaio não terminado sobre a questão meridional (GRAMSCI, 1987), ambos de outubro de $1926 .{ }^{1}$

O entendimento dos Cadernos e de sua estrutura é algo fundamental na medida em que uma análise neogramsciana acerca dos processos de construção e contestação da hegemonia no âmbito global demanda, necessariamente, a apresentação do pensamento gramsciano e a articulação entre os conceitos por ele desenvolvidos. Nesse processo, é de extrema relevância ler Gramsci buscando identificar seus limites e potencialidades para o entendimento do internacional. Assim, o presente artigo busca apresentar as contribuições dadas por uma perspectiva neogramsciana para o entendimento das dinâmicas de ordem e poder na economia política global. Para tal fim, o artigo divide-se em duas grandes partes: na primeira, será apresentado o pensamento de Gramsci em seu contexto para, em um segundo momento, ser desenvolvida uma releitura do autor para além de seu contexto; ou seja, um engajamento crítico com Gramsci que, se por um lado acaba por realmente "ir além” em alguns momentos, por outro se mantém nas sendas gramscianas em termos metodológicos e na "forma de pensar” (MORTON, 2007, p. 18). Assim, tal releitura ocorrerá a par- 
tir do engajamento com alguns autores neogramscianos, como Robert W. Cox, Stephen Gill, William I. Robinson, Adam Morton e John Agnew. Será feita uma discussão sobre a incorporação da obra de Gramsci na economia política global, com destaque para os impactos da globalização para a Pax Americana e, consequentemente, para o processo de internacionalização/transnacionalização do Estado.

\section{A problemática da hegemonia}

É notório o destaque que o conceito de hegemonia tem na obra de Gramsci como categoria teórico-política (SASSOON, 1980; LIGUORI, 2007; GRUPPI, 1978). A palavra hegemonia era frequentemente utilizada no início do século XX na Rússia para indicar a influência das classes trabalhadoras sobre as demais classes. Nesse contexto teórico-analítico, Gramsci ampliou o significado e o potencial heurístico do conceito ao utilizá-lo nos Cadernos para explicar os modos de dominação pela burguesia e para estabelecer uma base teórica para a contraestratégia proletária adequada para as novas formas políticas do capitalismo contemporâneo. Nesse sentido, trata-se de um argumento singular, capaz de caracterizá-lo como um autor em uma posição de renovação e conservação em relação a Marx e a Lenin.

A obra de Gramsci destaca o estudo dos fenômenos superestruturais, da política, da cultura, e do sistema de valores no contexto de uma ordem capitalista, contribuindo assim significativamente para a crítica ontológica de outras esferas do ser social que não especificamente a esfera econômica. Contudo, tal desenvolvimento se encontra em uma problemática que relaciona dialeticamente a superestrutura a uma base econômica. Isso fica claro quando as atenções são voltadas para as bases materiais da hegemonia: a hegemonia deve ser econômica também, já que as condições objetivas fornecem uma base para 
o estabelecimento daquela, que só poderá ser mantida por uma classe ou grupo que ocupe um lugar de destaque no sistema de produção. Assim, a condição para a reprodução do consentimento é que o sistema hegemônico produza resultados que, em certa medida, satisfaçam os interesses materiais de curto prazo de vários grupos sociais. Em suma, a hegemonia ideológica só pode ser mantida se estiver calcada em uma base material (GRAMSCI, 2002b, p. 48, Q13§18).

Não há, em Gramsci, uma supervalorização da subjetividade em detrimento da objetividade - o que o mantém coerente ao método ontológico-social marxiano. Se, por um lado, Gramsci não vê a economia como a mera produção de objetos materiais, recusando-se a vê-la como algo isolado da totalidade social, por outro ele não nega a "determinação em última instância" da totalidade social pela economia: “A estrutura e as superestruturas formam um 'bloco histórico', isto é, o conjunto complexo e contraditório das superestruturas é o reflexo do conjunto das relações sociais de produção" (GRAMSCI, 2004, p. 250, Q8§182). A ação do sujeito não ocorre no vazio, mas no interior de determinações econômico-objetivas que limitam, sem anular, a ação do sujeito.

O fator econômico não produz, assim, um fechamento final no sentido estrito de garantir um resultado; a determinação do econômico sobre o político e o ideológico só pode ocorrer em termos do estabelecimento anterior de limites que definam o terreno das operações. Em suma, Gramsci vê a determinação da política pela economia não como uma imposição mecânica de resultados unívocos e fatais mas como algo que condiciona "o âmbito das alternativas que se colocam à ação do sujeito” (COUTINHO, 2007, p. 97, ênfase nossa).

Neste contexto de interação entre economia, política e ideologia, é fundamental destacar que há, em Gramsci, uma diferenciação entre a regulamentação pela força e a regulamentação através do consenso, que corresponde "à natureza dúplice do centauro maquiavélico, feri- 
na e humana, da força e do consenso, da autoridade e da hegemonia" (GRAMSCI, 2002b, p. 33, Q13§14). Ora, tal diferenciação aponta para um contraste entre dois tipos ideais de supremacia: a dominação, que é o exercício de poder sem uma permissão crítica do governado, e a hegemonia ética, que seria uma liderança moral e intelectual sobre o governado (GRAMSCI, 2002a, p. 62-63, Q19\$24).

Coerção e consenso não são termos mutuamente excludentes: a força é um elemento constitutivo do consenso, pois qualquer ruptura deste traz à tona os mecanismos de coerção - intrínsecos a todas as esferas da vida social e que permanecem latentes enquanto o consenso se mostrar suficiente para manter a reprodução das relações sociais. "A coerção é, portanto, ubíqua; não se limita a qualquer instituição específica” (PRZEWORSKI, 1989, p. 198-199).

Isso se relaciona diretamente com o conceito de Estado ampliado, ou seja, com o caráter metodológico e não orgânico da distinção entre sociedade civil e sociedade política. Gramsci não apresenta um conceito culturalista de hegemonia, desconectado das relações de força. Na verdade, o fato dos organismos ligados à formação do consenso se encontrarem dialeticamente articulados à dimensão da força e da coerção possibilita afirmar que, "em Gramsci, existem força e consenso, não reductio ad unum" (LIGUORI, 2007, p. 35), apresentando assim uma "morfologia do poder na sociedade contemporânea" (LIGUORI, 2007, p. 21, ênfase nossa).

Nesse processo, as questões ideológicas são fundamentais, desempenhando o papel de "instrumentos consensuais da liderança intelectual e moral com relação às condições materiais" (MORTON, 2007, p. 91); ou seja, é fundamental levar em consideração o processo de organização da estrutura ideológica ou, em outras palavras, "'a organização material voltada para manter, defender e desenvolver a 'frente' teórica ou ideológica" (GRAMSCI, 2001b, p. 78, Q3\$49). Nota-se, assim, que, se por um lado a luta pela hegemonia é a luta de ideo- 
logias, por outro, não se trata apenas de uma luta de ideias, dado que estas possuem uma estrutura material à qual se encontram íntima e dialeticamente articuladas. É a ideologia que "empresta o cimento mais íntimo à sociedade civil e, portanto, ao Estado" (GRAMSCI, 2004, p. 375, Q10§41). É dada, assim, à dimensão ideológica um papel fundamental no processo de construção e manutenção da hegemonia, podendo ela ser vista, em última instância, como "lugar de construção de subjetividade" (LIGUORI, 2007, p. 91). Ou seja, a ideologia seria a representação da realidade de um grupo social, uma concepção de mundo fundamental na definição dos sujeitos coletivos. Esta concepção se encontra em um momento anterior às escolhas individuais, condicionando "os comportamentos mais ligados à vontade" (LIGUORI, 2007, p. 95) ao mesmo tempo em que mantém uma relação dialética com estes.

Em tal processo de construção e manutenção da hegemonia, a "direção intelectual e moral" deve ser exercida no campo das ideias e da cultura, manifestando capacidade de conquistar o consenso e de formar uma base social, pois não há direção política sem consenso. A hegemonia cria, assim, a subordinação de outros grupos sociais, que se refere à submissão às ideias, e não apenas à força. A classe dominante repassa a sua ideologia e realiza o controle do consenso através de uma rede articulada de instituições culturais, os "aparelhos privados de hegemonia" - escola, igreja, jornais e demais meios de comunicação -, cuja finalidade principal é inculcar nas classes dominadas a subordinação passiva, através de um complexo emaranhado de ideologias formadas historicamente. Quando isso ocorre, a subordinação social das classes também se torna política e cultural; ou seja, se o âmbito econômico é um aspecto fundamental de toda a problemática gramsciana, é o reino da política que é o "momento do mais alto desenvolvimento histórico de uma classe” (SASSOON, 1980, p. 116).

Assim, hegemonia seria determinar as características de um determinado processo histórico. É tornar-se o protagonista de reivindicações 
que são de outros estratos sociais, unificando-os através de parâmetros ideológicos e mantendo-os unidos. A hegemonia não é apenas política, mas é também um fato cultural, moral, enfim, de concepção de mundo. Em suma, é a capacidade que uma classe ou grupo tem de unificar e de manter unido, através da ideologia - e da realidade material -, um bloco social que não é homogêneo, mas marcado por contradições de classe. Cria-se então uma vontade coletiva que tem como finalidade a consecução de um projeto econômico-político-social que envolve a constituição/reprodução de uma determinada ordem social (MELLO, 1996).

\section{Os intelectuais e a construção do bloco histórico}

Buscando entender a problemática da hegemonia, bem como o processo através do qual uma classe subalterna remodela as forças sociais, Gramsci desenvolveu o conceito de bloco histórico. Em uma situação na qual uma classe hegemônica é a classe dominante em uma formação social, o Estado (ampliado) mantém a coesão e a unidade dentro do bloco mediante a difusão de uma cultura comum. Por outro lado, um novo bloco se forma quando uma classe subalterna estabelece sua hegemonia sobre os outros grupos subordinados. Este processo requer um intensivo diálogo entre os líderes e os seguidores dentro de uma classe que aspira a hegemonia, o que remete ao papel dos intelectuais. Estes desempenham uma função social central na mediação da luta pela hegemonia desenvolvendo e sustentando as imagens mentais, as tecnologias e as organizações que mantêm coesos os membros de uma classe e de um bloco histórico em uma identidade comum (GRAMSCI, 2001b, p. 21, Q12§1).

Os intelectuais não se encontram limitados apenas às questões técnicas da produção, mas também dão à classe dominante a consciência de si mesma e de sua própria função, tanto na esfera social quanto na 
esfera política; ou seja, dão homogeneidade à classe dominante e à sua direção. Ora, isso remete ao fato de que qualquer grupo social que se estabeleça na esfera econômica deve desenvolver sua própria hegemonia política e cultural, criando seus próprios quadros de intelectuais. Tais questões deixam claro o fato de que, para Gramsci, as ideias não são "arbitrárias" ou meros epifenômenos;

[...] são fatos históricos reais, que devem ser combatidos e revelados em sua natureza de instrumentos de domínio [...] para tornar os governados intelectualmente independentes dos governantes, para destruir uma hegemonia e criar outra, como momento necessário da subversão da práxis (GRAMSCI, 2004, p. 387, Q10§41).

Isso retoma as questões anteriores vinculadas à relação intrínseca entre materialidade e subjetividade na luta ideológica. A percepção correta acerca da "estrutura material da ideologia" (GRAMSCI, 2001b, p. 78, Q3\$49) é fundamental para que se perceba como pressões indiretas são capilarizadas na sociedade no processo de construção da hegemonia, sendo possível ver Gramsci como um “teórico do poder capilar” (MORTON, 2007, p. 92). Se a hegemonia é a luta pela subjetividade, ou seja, pela transformação e construção de formas intersubjetivas de consciência no âmbito da sociedade civil, então ela só é alcançada quando o subordinado acredita que a autoridade que existe sobre ele emana do próprio self (BIELER; MORTON, 2008; MORTON, 2007).

Nota-se neste ponto a relevância de uma perspectiva (neo)gramsciana face às críticas de inspiração pós-estruturalista: o mundo social adquire um significado "objetivo", aparentando ser "real" em si devido ao processo de reificação, ou seja, a partir do momento em que as relações internas características do capital assumem a forma de relações externas em função da alienação do trabalho em um contexto de capitalismo. Assim, diferentemente do pós-estruturalismo - com 
destaque para as leituras inspiradas em Foucault - que parte de uma ontologia totalizante na qual "as relações de poder [...] são a fonte constitutiva singular de toda a prática humana" (BRUFF, 2009, p. 341 ), ${ }^{2}$ uma perspectiva (neo)gramsciana parte de uma ontologia social não reducionista e sem garantias finais, que toma como ponto de partida a organização social da produção e os processos de objetificação através dos quais os seres humanos passam a existir socialmente (RUPERT, 1994; BIELER; MORTON, 2008). Isso ocorre porque a "produção cria a base material para todas as formas de existência social" e, além disso, "as formas nas quais os esforços humanos são combinados em processos produtivos afetam todos os demais aspectos da vida social, incluindo a política" (COX, 1987, p. 1).

Consequentemente, diferentemente do pós-estruturalismo, que vê o significado do mundo não discursivo apenas a partir de categorias constituídas discursivamente, para Gramsci o mundo ideacional só adquire força "independente" em sua relação dialética com as relações sociais de produção. Só assim tais ideias adquirem organicidade e influenciam a percepção dos seres humanos sobre o mundo que os cerca. Como afirma Stuart Hall (apud BIELER; MORTON, 2008, p. 12), "tudo está na esfera discursiva, mas nada é apenas discurso ou apenas discursivo". Isso não significa que formas de identidade que não se encontrem diretamente relacionadas às questões de classe sejam negligenciadas; na verdade, tais formas de identidade são embasadas nas realidades sociais que estão relacionadas ao processo produtivo (COX, 1987; BIELER; MORTON, 2008; RUPERT, 2003; BAKKER; GILL, 2003).

Para entender tal processo, é fundamental voltar ao conceito de bloco histórico, pois este diz respeito àquelas situações em que há um alto grau de congruência política entre três tipos de relações de forças. A primeira seria o nível estrutural ou material, vinculado ao nível das forças sociais de produção. A segunda é política, relacionada ao desenvolvimento das classes e de seu nível de consciência política. Já a 
terceira é militar, relacionada tanto ao uso doméstico do poder militar quanto às forças militares geopolíticas que configuram o desenvolvimento de uma sociedade particular.

No movimento em direção à hegemonia e à criação de um bloco histórico, haveria, dentro do segundo tipo de relação de força - categoria das forças políticas -, três níveis ou três momentos no desenvolvimento da consciência. O primeiro, o "econômico-corporativo", reflete os interesses específicos de um grupo particular, ou uma solidariedade de grupo. O segundo, a "consciência de classe", estende-se a toda uma classe social, mas permanece no nível dos interesses puramente econômicos. Por fim, o terceiro, "hegemônico", coloca em harmonia os interesses das classes dominantes com os interesses das classes subordinadas transcendendo tais interesses em direção a uma ideologia que se expressa em termos universais. O movimento em direção à hegemonia é, assim, uma passagem da estrutura para o âmbito das superestruturas complexas, dos interesses específicos de um grupo ou classe para a construção de instituições e elaboração de ideologias. Caso reflitam uma hegemonia, essas instituições e ideologias não aparentarão promover os interesses de uma classe específica, mas serão universais em sua forma. Ou seja, satisfarão alguns dos interesses dos grupos subordinados sem minar a liderança e os interesses da classe hegemônica (GRAMSCI, 2002b, p. 36-46, Q13§17). Não obstante, nem sempre prevalece, como resultado do embate das forças sociais, situações hegemônicas. Passemos, assim, para uma leitura acerca de situações deste tipo.

\section{A questão da revolução-restauração ou da revolução passiva}

De acordo com Gramsci, nem todas as sociedades ocidentais seriam hegemonias burguesas. Haveria dois tipos de sociedade: o primeiro 
teria passado por uma revolução social que culminou no estabelecimento de novos modos de produção e de relações sociais. O segundo seriam aquelas sociedades que importaram ou foram forçadas a adotar alguns aspectos de uma nova ordem criada externamente sem abandonar completamente a velha ordem. Neste caso, a dialética revolução-restauração tende a bloquear uma vitória tanto das velhas quanto das novas forças sociais, o que demonstra que em tais sociedades a burguesia falhou em atingir a condição de hegemonia. Isso é o que Gramsci chamou de revolução passiva.

Não se trata de algo literalmente "passivo", mas articulado a um processo "revolucionário" que ocorre através da intervenção estatal ou da inclusão de novos grupos sociais no bloco histórico. É uma mudança social da qual são excluídos os interesses das classes subalternas, o que revela a pertinência do conceito para descrever situações de "revolução pelo alto". 3 Tal revolução é, assim, "marcada por uma violenta revolta social, mas envolve uma elite relativamente pequena liderando a criação de um poder estatal e de uma estrutura institucional consoante com as relações capitalistas de propriedade" (MORTON, 2007, p. 66). O internacional é assim visto como um processo historicamente integrado, em que as revoluções passivas são "parte de um processo cumulativo de momentos de formação estatal historicamente ligados dentro da ordem mundial de mercado do capitalismo e do sistema internacional". Neste sentido, são "casos específicos de transição estatal que são internamente relacionados através das condições histórico-mundiais gerais de desenvolvimento desigual e combinado" (MORTON, 2007, p. 71, ênfases no original).

Central neste ponto é a capacidade de adaptação interna das relações de produção capitalistas aos desenvolvimentos das forças produtivas, ou seja, "certa plasticidade" que lhe dá condições de " "se reestruturar' em períodos de crise" (BUCI-GLUCKSMANN, 1978, p. 121). 
Os dois aspectos principais que acompanham o fenômeno da revolução passiva são o cesarismo e o transformismo. O primeiro diz respeito à intervenção de um "homem forte" buscando por fim o embate entre forças sociais opostas e iguais (GRAMSCI, 2002b, p. 76, Q13\$27). Já o transformismo se refere a um método para implementar um programa limitado de reformas através da cooptação de líderes potenciais dos grupos sociais subalternos (GRAMSCI, 2002a, p. 286-287, Q8\$36). Assim, o transformismo pode funcionar como uma estratégia de assimilação e domesticação de ideias potencialmente perigosas mediante o ajuste destas às políticas da coalizão dominante. Mas qual seria a relação entre revolução passiva e hegemonia? Ora, a revolução passiva seria a contrapartida da hegemonia, "o exercício de uma hegemonia restrita" em um momento histórico no qual as forças dominantes perderam "a capacidade de assimilar a seu projeto as classes subalternas" (BIANCHI, 2006, p. 48).

Tal conceito não se limita às transições passivas, mas também "envolve os modos de reestruturações passivas do próprio capitalismo" (BUCI-GLUCKSMANN, 1978, p. 135, ênfase no original). Neste sentido, um exemplo seria o relacionamento existente entre a forma mais dinâmica de poder produtivo e a economia política no início do século XX - americanismo e fordismo - e as formas mais atrasadas de economia política na Europa. A dialética entre hegemonia e revolução passiva é um tema central do Caderno 22, "americanismo e fordismo": ambos representavam uma aceleração de uma nova forma social baseada sobre uma profunda relação orgânica entre forma de Estado, sociedade civil e modo de produção, e, como tal, representava uma nova forma de economia planejada na qual a hegemonia era baseada nas forças de produção. Em contraste, a estrutura de classe europeia envolvia muitos elementos parasitas. A burguesia não era hegemônica nessas sociedades da Europa e, dessa maneira, as transformações tomaram a forma de revolução passiva - o que ajudaria a 
entender os desdobramentos das correlações de força ao longo do século XX.

\section{Lendo Gramsci para além de seu contexto}

Surge, neste ponto, uma pergunta central: "como se situa o pensamento de Gramsci em face dos fenômenos econômico-sociais hoje mais debatidos, em primeiro lugar globalização [...]?" (LIGUORI, 2007, p. 59). Assim, mais do que tentar aplicar Gramsci de maneira literal, partindo do pressuposto de que ele possui a chave interpretativa para vários problemas históricos e contemporâneos, a grande questão que se coloca é "pensar de uma maneira gramsciana" (MORTON, 2007); ou seja, incorporar o método gramsciano na análise de condições sociais e históricas distintas daquelas que foram o foco das atenções de Gramsci. É com este objetivo que são desenvolvidas as seções seguintes, buscando identificar os principais elementos das contribuições neogramscianas para o entendimento das dinâmicas de ordem e poder na economia política global.

\section{Robert W. Cox, as relações internacionais e as três esferas de atividade da hegemonia}

Os padrões das relações de produção seriam, conforme Cox (1987), o ponto de partida para a análise tanto da operação quanto dos mecanismos de hegemonia. Dado o caráter fundamental da relação entre produção e poder, Cox busca analisar como o poder nas relações sociais de produção dá origem a certas forças sociais, como estas forças sociais se tornam as bases do poder nas formas de Estado, e como estas formas de Estado moldam a ordem mundial. Seriam, assim, três as esferas de atividade que constituem uma estrutura histórica: (1) a 
organização da produção, com destaque para as forças sociais engendradas pelo processo de produção; (2) as formas de Estado, relacionadas aos complexos Estado/sociedade civil historicamente contingentes; e (3) as ordens mundiais, isto é, as configurações particulares de forças que definem sucessivamente a problemática da guerra e da paz (COX, 1996a, p. 100).

Nota-se, neste ponto, a proximidade existente entre esta revisão acerca das relações de poder e as relações de força desenvolvidas por Gramsci (MORTON, 2007). Não há um relacionamento unilateral entre as três esferas de atividade, podendo variar o ponto de partida para explicar o processo histórico (COX, 1996a). Além disso, em cada uma das três esferas de atividade há três outros elementos que se combinam dialeticamente para constituir uma estrutura histórica: (1) ideias, entendidas como significados intersubjetivos e como imagens coletivas sobre a ordem mundial; (2) capacidades materiais, concernentes aos recursos acumulados; e (3) instituições, que são o amálgama entre os dois elementos anteriores.

A partir desse quadro, Cox analisa as estruturas históricas que têm existido temporalmente no sistema capitalista de produção, fazendo uma leitura acerca dos principais elementos que constituem o mundo social e, neste sentido, as relações entre os agentes e as estruturas sociais em que estes estão inseridos. Seu ponto de partida é a ordem mundial, e é a partir desse ponto que a noção gramsciana de hegemonia começa a desempenhar um papel, mesmo que discreto, em seu arcabouço teórico (COX, 1987).

Retomando Gramsci, percebe-se que mudanças na ordem mundial como mudanças no equilíbrio geopolítico e estratégico-militar - remontam a mudanças fundamentais nas relações sociais. Além disso, toda relação de hegemonia ultrapassa os limites de uma nação específica, envolvendo relações mais complexas e tendo como base de atuação não o Estado especificamente, mas o âmbito mundial 
(GRAMSCI, 2002b, Q13§2; GRAMSCI, 2004, Q10§44). O Estado permanece sendo fundamental nas relações internacionais e em uma relação social "através da qual o capitalismo e a hegemonia são expressos" (MORTON, 2007, p. 120). Contudo, o Estado é entendido em seu sentido "ampliado", o que inclui sua própria base social e rompe com a "estatolatria" (GRAMSCI, 2002b, p. 279-280, Q8§130), ou seja, com visões mais estreitas e superficiais do Estado que o reduzem à burocracia responsável pela política externa ou às capacidades militares estatais.

Nesse processo, a construção de um bloco histórico passa por um "momento nacional" em que uma classe hegemônica se manifestaria como um fenômeno internacional na medida em que desenvolve uma forma particular de relações sociais de produção. Ou seja, uma vez que a hegemonia tenha sido consolidada domesticamente, ela pode se expandir para além de uma ordem social particular, em uma escala mundial (COX, 1987, p. 149-150). O Estado condensa, assim, uma relação hegemônica entre classes dominantes e frações de classes, tornando os diversos interesses e aspirações destas coerentes e compatíveis (MORTON, 2007; VAN DER PIJL, 1994, 1998), sendo que em tal relação as classes e frações de classes muitas vezes se encontram articuladas a forças sociais externas ao Estado - transnacionais e globais -, o que torna ainda mais complexos os embates pela construção de um projeto hegemônico. A hegemonia pode, dessa forma, ser operada em dois níveis: pela construção de um bloco histórico e pelo estabelecimento da coesão social dentro de uma forma de Estado, bem como mediante a expansão internacional de um modo de produção e pela projeção dessa hegemonia através da ordem mundial. Todavia, para Cox, o "momento nacional" é condição sine qua non nesse processo: "uma hegemonia mundial é assim no seu início uma expansão de uma hegemonia interna (nacional) estabelecida por uma classe social dominante" (COX, 1994, p. 61). 
O "momento nacional" é assim o ponto de partida com relação à espacialidade do desenvolvimento e expansão do capitalismo (MORTON, 2007; AGNEW, 2005). Contudo, é também o "ponto de chegada", pois a luta pela hegemonia implica transformar interesses particulares, vinculados a uma forma particular de Estado, em algo capaz de ser aplicado não apenas no local onde surgiu, mas em vários Estados - ou seja, potencialmente universalizável (GRAMSCI, 2002b, p. 315, Q14\$68).

Em suma, a falha em reconhecer a espacialidade do pensamento de Gramsci (JESSOP, 2005) pode levar ao equívoco de sobrevalorizar aqueles que seriam os supostos "limites nacionais" de Gramsci. Isso ocorre, por exemplo, em Randall Germain e Michael Kenny (1998, p. 20) quando estes afirmam que "a natureza histórica de seus conceitos [de Gramsci] significa que eles receberam seus significados e poder explanatório primeiramente de sua base nas formações sociais nacionais, e foram usados exclusivamente por Gramsci nestes termos". Joseph Femia, por sua vez, embora reconheça que a hegemonia poderia ter um espectro de atuação que fosse para além das fronteiras nacionais, não é capaz de lidar com o fato de os Estados serem pontos nodais e não dominantes; neste sentido, afirma que, para o autor sardo, "o mundo é naturalmente dividido em unidades 'nacionais' separadas [...] e estas são os principais atores do âmbito internacional" (FEMIA, 2005, p. 345). Da mesma forma, Robbie Shilliam (2004) equivoca-se ao afirmar que Gramsci não concede status constitutivo ao âmbito internacional. Na verdade, no que concerne à questão da hegemonia, "a restrição de sua aplicabilidade unicamente ao 'momento nacional', se não tematizada com o devido cuidado, pode conduzir a uma dissimulação equivocada [...] do potencial teórico do conceito, de seu alcance sociológico" (MELLO, 1996, p. 26). Neste sentido, para entender a relação entre o Estado, em seu sentido ampliado, e os processos de globalização, faz-se fundamental voltar as atenções para o conceito de internacionalização do Estado e seus respectivos desdobramentos. 


\section{Ordem e Poder na Economia Política Global: A}

Contribuição Neogramsciana

\section{Internacionalização do Estado, Pax Americana e globalização}

Há, em Gramsci, uma preocupação com a articulação existente entre os problemas ditos "nacionais" e o contexto "internacional" no qual tais problemas se encontravam inseridos. Este é o caso da atenção dispensada ao papel dos Estados Unidos na economia política global, em termos tanto de sua relevância para a economia e para as finanças mundiais (GRAMSCI, 2001a, p. 298-299, Q5§8; GRAMSCI, 2002b, p. 129-136, Q2\$16) quanto de suas ações de "sobrepor uma rede de organizações e movimentos guiados por eles" (GRAMSCI, 2001a, p. 292, Q3\$5) - com destaque para as associações voluntárias e organizações privadas e públicas que operavam "promovendo o liberalismo americano e apoiando a projeção universal da produção de massa" (MORTON, 2007, p. 100), como Rotary Club, Associação Cristã de Moços e Movimentos Pancristãos, por exemplo (GRAMSCI, 2002c, 346-349, Q1§61; 2002b, p. 151, Q2§46; 2001a, p. 185, Q2§135; p. 295-298, Q5§2; p. 195-196, Q5\$17; p. 299-301, Q5\$61). Ora, isso é relevante, pois ajuda a perceber o equívoco presente em críticas que apontam uma aplicação exclusiva das categorias gramscianas ao âmbito nacional ou afirmam a negação, por parte de Gramsci, do âmbito internacional como fator causal ${ }^{4}$ da transformação social. Na verdade, os conceitos de hegemonia (desde sua concepção pré-cárcere) e revolução passiva possuem um potencial heurístico que vai além do contexto "nacional", apontando para o fato de que "a perspectiva é internacional e não pode deixar de ser" (GRAMSCI, 2002b, p. 314, Q14§68). Há, assim, no Caderno 14 uma fecunda linha de raciocínio para lidar com a relação entre o global e o nacional:

Realmente, a relação "nacional” é o resultado de uma combinação "original" única (em certo sentido), que deve ser compreendida e concebida nesta originalidade e unicidade se se quer 
dominá-la e dirigi-la. Por certo, o desenvolvimento é no sentido do internacionalismo, mas o ponto de partida é "nacional", e é deste ponto de partida que se deve partir. Mas a perspectiva é internacional e não pode deixar de ser. É preciso, portanto, estudar exatamente a combinação de forças nacionais que a classe internacional deverá dirigir e desenvolver segundo a perspectiva e as diretrizes internacionais (GRAMSCI, 2002b, p. 314, Q14§68).

Tal questão deve ser vista à luz das críticas de Gramsci à "estatolatria”, o que destaca a forma peculiar pela qual Gramsci entende o "momento nacional": colocando-se contra os conceitos não nacionais, ou seja, contra um cosmopolitismo que subestime a necessidade de "nacionalização" das classes - sem, contudo, restringir o momento da hegemonia apenas a este âmbito da luta política. Não há, como visto, uma relação unilateral entre as três esferas de atividade propostas por Cox, e o ponto de partida para explicar o processo histórico pode variar. Ora, isso é fundamental, já que destaca o fato de que, embora se possa partir do "nacional", este é um ponto de partida nodal e não dominante na relação com o "internacional", o que é perfeitamente consistente com a percepção espacial de Gramsci (MORTON, 2007).

Central na releitura de Gramsci na economia política global é a percepção dos impactos que a intensificação de determinados processos de internacionalização da produção exerce no âmbito da política. Ou seja, a percepção da internacionalização do Estado, processo fundamental para o entendimento dos mecanismos usados para a manutenção da hegemonia no período da Pax Americana, bem como para o entendimento do contexto que emerge a partir da intensificação dos processos de globalização. A internacionalização do Estado seria "um processo global pelo qual as políticas e as práticas nacionais têm sido ajustadas às exigências da economia mundial" (COX, 1987, p. 
253). Os Estados têm se tornado parte de uma estrutura política complexa emergente em escala internacional, o que leva a duas questões: (1) o Estado não desaparece nesse processo, mas com a emergência do "global" um novo âmbito de interações sociais surge sem que isso implique a subsunção ou a hierarquização dos demais âmbitos (COX, 1987, p. 253); (2) tal processo não é homogêneo. Na verdade, destacar o "momento nacional" ajuda a ver as "articulações interescalares" (MORTON, 2007, p. 138) existentes entre os âmbitos nacional e internacional; ou seja, é fundamental perceber as dinâmicas espaciais da dialética da globalização.

Nota-se, então, um processo de transformação das estruturas políticas estatais, que ocorre a partir de novos alinhamentos das relações de poder entre os grupos domésticos e destes com grupos de outros Estados em um processo mais amplo de construção de um bloco histórico para além dos limites do Estado nacional. Há, assim, a formação de um consenso interestatal relacionado às necessidades da economia mundial. A partir daí, as estruturas internas dos Estados partícipes deste processo são ajustadas a fim de traduzir tal consenso em políticas públicas nacionais.

Desde o surgimento do Sistema de Bretton Woods, o Estado começa a ocupar uma posição de mediação entre as estruturas da economia internacional e da economia mundial. Ou seja, durante a Pax Americana, há a prevalência de uma ordem mundial hegemônica em que se destaca, nos Estados industriais avançados, uma forma de Estado na qual este prestava contas tanto às instituições da economia mundial FMI e Banco Mundial, por exemplo - quanto à opinião pública doméstica. Tal questão se expressava na ideia de "liberalismo incrustado" (RUGGIE, 1982) ou na possibilidade de se combinar livre-comércio no âmbito internacional com intervenção estatal no âmbito doméstico a fim de garantir a estabilidade. Nesse processo de mudança do centro de gravidade da economia nacional para a economia mundial, o Estado permanecia como responsável pela estabilidade 
em ambos os âmbitos. Tal processo pressupunha uma estrutura de poder em que agências e componentes do governo estadunidense tinham uma posição de destaque. Contudo, esta estrutura de poder não operava "de cima para baixo" nem exclusivamente a partir dos Estados nacionais. Como todo processo de construção de uma hegemonia, pressupunha uma identificação por parte dos subordinados; assim, os processos de internacionalização do Estado devem ser entendidos de maneira dialética, como uma tendência que gera contradições e movimentos de oposição.

A ordem mundial hegemônica estabelecida pela Pax Americana "foi fundada por um país no qual a hegemonia social tem sido estabelecida e no qual tal hegemonia foi suficientemente expansiva para se projetar em uma escala mundial" (COX, 1987, p. 266). Nesse mesmo processo, o modo fordista de produção e uma determinada forma de Estado tornaram-se os modelos mundiais, sendo tanto exportados quanto emulados alhures. Há, assim, por detrás da Pax Americana uma visão de hegemonia, herdeira do sucesso do New Deal e associada ao internacionalismo econômico pelo qual grupos sociais estadunidenses buscavam estimular a demanda por meio do consumo de massa. Isso é fundamental, pois expressa a relevância da dimensão espacial na construção de uma hegemonia: "o lugar que vem exercer a hegemonia importa, assim, para o conteúdo e para a forma que a hegemonia assume" (AGNEW, 2005, p. 9). No caso da Pax Americana, "uma dialética espacial entre os Estados Unidos e o resto do mundo mais propriamente do que uma dialética histórica conjuntural/universal com aspectos geográficos meramente acidentais" é fundamental para a compreensão da economia política global contemporânea (AGNEW, 2005, p. 9).

Tal hegemonia possuía certas particularidades. Sua geografia do poder derivava do poder em rede há muito "cultivado na sociedade de mercado americana" (AGNEW, 2005, p. 61), o que levou a uma crescente internacionalização da produção e das finanças gerando conse- 
quências significativas, como a própria erosão dos princípios norteadores da ordem mundial no período da PaxAmericana. Neste processo, "o modelo econômico-cultural dos Estados Unidos e sua posição global hegemônica" (AGNEW, 2005, p. 61) foram fundamentais, sendo possível perceber uma crescente integração dos processos de produção em uma escala global através de determinados processos de articulação das corporações transnacionais em diferentes localizações territoriais. É possível, assim, afirmar que, de uma perspectiva neogramsciana, "esta organização da produção e das finanças em um nível transnacional distingue fundamentalmente a globalização do período da Pax Americana" (MORTON, 2007, p. 124).

\section{Os processos de globalização e a passagem da internacionalização para a transnacionalização do Estado}

Apesar de sua relevância, a tese de internacionalização do Estado foi alvo de críticas à ênfase dada inicialmente por Cox ao papel dos Estados em um contexto de hegemonia neoliberal - o de correia de transmissão para o neoliberalismo, do âmbito global para o âmbito local (COX, 1996b). Neste sentido, para Leo Panitch (1997, p. 89-96), tal tese enfatizaria desproporcionalmente o aspecto top down das relações de poder, vendo a globalização como um processo unidirecional, do global para o nacional. Desta forma, Cox negligenciaria o fato de que a globalização é obra dos Estados. Já L. H. M. Ling (1996) e Andrew Baker (1999) afirmam que o conceito de internacionalização do Estado seria limitado pois negligencia as interações recíprocas existentes entre o global e o local assim como as relações sociais que se reforçam mutuamente na economia política global, além de desconsiderar o papel dos conflitos de classe dentro das formações sociais nacionais. Pinar Bedirhanoglu (2008), por sua vez, argumen- 
ta que Cox parte de uma leitura equivocada do conceito marxiano de modo de produção, o que o leva a uma concepção fetichizada do Estado e, consequentemente, a uma reprodução das práticas ideológicas (neo)liberais. Em suma, para tais autores, o papel do Estado ainda seria determinado pelas lutas entre as forças sociais localizadas dentro de cada formação social particular, embora as forças sociais possam estar inseridas em estruturas transnacionais - o que apontaria para os limites do conceito desenvolvido por Cox.

O próprio Cox reconhece a pertinência, em alguma medida, da crítica à ideia de "correia de transmissão": tal metáfora teria levado a uma leitura equivocada de que haveria uma força totalmente externa impactando os Estados, obscurecendo "o papel do equilíbrio das forças sociais dentro do Estado e do potencial de resistência à globalização das forças sociais hostis" (COX, 2002, p. 33). ${ }^{5}$ A ideia de nébuleuse ajudaria a captar tal questão, devendo ser vista como algo incompleto e permeado de contradições - e não uma força progressivamente centralizadora. Neste sentido, o capitalismo global seria um processo que ocorre em múltiplos níveis,

\begin{abstract}
determinado no nível doméstico pelo equilíbrio das forças sociais dentro dos Estados, no nível transnacional por uma ideologia neoliberal [...], no nível internacional por aquelas instituições que desenvolvem diretrizes políticas oficialmente aceitas, e novamente no nível nacional mediante a tradução de tais diretrizes em medidas concretas de políticas monetárias e fiscais (COX, 2002, p. 33).
\end{abstract}

Ou seja, há, em um segundo momento, a percepção por parte de Cox sobre os limites da metáfora da "correia de transmissão". Tal esclarecimento é relevante, pois responde certas críticas que afirmam uma suposta negligência, pelos neogramscianos, em explicar como os Estados respondem às influências externas e como a dimensão doméstica das relações de classe se enquadra nesse processo (WORTH, 
2008). Além disso, a obra de Morton (2007) é fundamental, pois demonstra a relação existente entre a obra de Cox e a obra de Gramsci, contribuindo, assim, para inserir tal discussão no campo do materialismo dialético. Além disso, desde 1981, quando o conceito foi desenvolvido, Cox alertava para a necessidade de pesquisas empíricas que indicassem como tal processo de internacionalização do Estado ocorria na prática.

A incorporação da globalização como categoria analítica leva não apenas ao surgimento do conceito de internacionalização do Estado, mas também ao seu desenvolvimento, o que contribui para a superação das críticas acima elencadas. Stephen Gill contribuiu para o entendimento desse processo como parte do caráter cambiante da hegemonia mundial centrada nos Estados Unidos, em especial em sua análise sobre a Comissão Trilateral (GILL, 1990). Como Cox, Gill vê a reestruturação global da produção em linhas pós-fordistas ocorrendo em um contexto de mudança estrutural nos anos 1970. É nesse período que haveria uma transição de um bloco histórico internacional para um bloco histórico liberal transnacional.

Há, assim, a partir do pós-Segunda Guerra Mundial, um rápido processo de internacionalização da produção e, concomitantemente, nota-se uma integração dos mercados de capital e de câmbio em escala global. Tanto os governos nacionais quanto os trabalhadores são cada vez mais constrangidos pelos recursos de poder e pela crescente mobilidade do capital transnacional (GILL; LAW, 1989). Nesse processo, há a mobilização da emergente fração transnacional da classe capitalista, que passa a desenvolver uma consciência e uma solidariedade que se expressam, por exemplo, em organizações internacionais, instituições financeiras internacionais e conselhos privados de relações internacionais. Assim, tal fração da classe capitalista passa, cada vez mais, a ocupar o centro de um emergente bloco histórico liberal transnacional, que conta com uma liderança mais ampla que a hegemonia transatlântica do período anterior e com uma menor in- 
corporação dos setores trabalhistas. ${ }^{6}$ Gill contribui, assim, para a tese coxiana da internacionalização do Estado e, por meio do conceito de transnacionalização do Estado, busca, a partir de uma mudança semântica, destacar a relevância dos atores transnacionais:

[...] um processo por meio do qual as políticas estatais e os arranjos institucionais são condicionados e mudados pelo poder e pela mobilidade das frações transnacionais do capital. Nos anos 1970 e 1980, isso deu um crescente peso para certas partes do governo, como os Ministérios da Finança e da Economia (GILL, 1990, p. 94).

Segundo Gill, a supremacia é organizada em âmbito global mediante dois processos: novo constitucionalismo e neoliberalismo disciplinar, concomitante à difusão da civilização de mercado. O neoliberalismo disciplinar seria a expressão de uma contrarrevolução do capital em escala mundial ocorrida nos anos 1990, que reconstitui o Estado e o capital, assim como intensifica as hierarquias sociais associadas com as relações de classe, raça e gênero em escala mundial. Tal revolução envolve a extensão dos processos de "comodificação" e alienação baseados na intensificação da disciplina do capital nas relações sociais. Ou seja, é uma forma concreta de poder estrutural e comportamental combinando o poder estrutural do capital com o "poder capilar" e o "panopticismo" (GILL, 2003). Esse neoliberalismo disciplinar é institucionalizado por meio da reestruturação do Estado e das instituições internacionais, envolvendo a imposição de novas estruturas legais e políticas constitucionais ou quase-constitucionais, o que é chamado de novo constitucionalismo, "o projeto político de fazer do liberalismo transnacional, e se possível do capitalismo democrático liberal, o único modelo para o desenvolvimento futuro" (GILL, 2003, p. 131-132). Ligada a esse projeto, encontra-se a tentativa de disseminação global de uma civilização de mercado baseada em uma ideologia do progresso capitalista. 
Nesse mesmo caminho, William I. Robinson (2004) desenvolve uma teoria do capitalismo global. Para ele, a globalização representaria "uma mudança epocal" (ROBINSON, 2004, p. 4) marcada pela emergência de uma classe capitalista transnacional e de um Estado transnacional. Ora, dado que a acumulação do poder acompanha a acumulação do capital, a partir das novas configurações globais dos processos de acumulação capitalista perceber-se-ia a emergência de um Estado transnacional a partir de dentro do sistema interestatal. Uma vez que as circunstâncias materiais que serviram de base para o surgimento dos Estados nacionais estão sendo superadas pela globalização, torna-se necessária uma releitura do Estado como uma relação social específica inserida em estruturas sociais mais amplas que pode tomar formas institucionais historicamente determinadas (ROBINSON, 2001). Nesse sentido, o Estado-nação não mais poderia ser visto como contêiner dos processos de acumulação do capital, da formação das classes ou do desenvolvimento, dado que tais processos se encontram cada vez mais em um contexto de globalização (ROBINSON, 2010). Tal Estado transnacional é definido como

[...] uma constelação particular de forças e relações de classes vinculadas à globalização capitalista e ao surgimento de uma classe capitalista transnacional, incorporada em uma diversa gama de instituições políticas. Estas instituições são Estados nacionais transformados e instituições supranacionais diversas que servem para institucionalizar a dominação desta classe como a fração hegemônica do capital mundial. [...] [Tal aparato] compreende aquelas instituições e práticas na sociedade global que mantêm, defendem e avançam a hegemonia emergente de uma burguesia global e de seu projeto de construir um novo bloco histórico capitalista global (ROBINSON, 2001, p. 166).

Tal aparato regulatório-coercitivo diz respeito a uma rede emergente sem uma forma institucional centralizada que compreende Estados 
nacionais integrados e transformados juntamente com fóruns econômicos e políticos supranacionais. A transformação dos Estados nacionais e o surgimento de instituições supranacionais não seriam, assim, aspectos distintos ou mutuamente excludentes, mas duas dimensões de um mesmo processo de transnacionalização do Estado. Tais instituições supranacionais têm paulatinamente suplantado as instituições domésticas com relação à formulação e ao desenvolvimento de políticas e gerenciamento da economia global. É nesse sentido que se desenvolve a releitura do conceito de transnacionalização do Estado: os Estados nacionais estão deixando de ser os formuladores das políticas nacionais para serem os administradores das políticas formuladas pelas instituições supranacionais - em suma, tornando-se "um componente funcional de um Estado transnacional mais amplo" (ROBINSON, 2004, p. 100).

Nesse processo, os Estados Unidos devem ser vistos como a instituição política do aparato supranacional que exerce uma espécie de liderança no desenvolvimento de estratégias e políticas em nome do capital global - uma espécie de "ponto de condensação material" das pressões dos grupos dominantes do mundo inteiro a fim de resolver os problemas e garantir a reprodução do capitalismo global - devido a uma série de razões, dentre as quais se destacam o fato da intensificação dos processos de globalização ter ocorrido no período em que os Estados Unidos exerciam o domínio mundial e o fato de que os Estados Unidos concentram em si a esmagadora maioria de recursos bélicos e financeiros, o que lhes dá certa preponderância para agir em nome das "elites globalizantes". Ou seja, há a necessidade de que exista uma "autoridade política" capaz de garantir o ambiente necessário para que ocorra a reprodução ampliada do capital em escala global (ROBINSON, 2004). As intervenções estadunidenses são vistas não como uma reprodução da velha lógica imperialista, mas como um engajamento na troca das elites governantes - trocam-se elites local e regionalmente orientadas por elites mais favoráveis ao projeto 
transnacional, como nas intervenções na América Latina e no caso da invasão do Iraque (ROBINSON, 1996, 2004).

Apesar dos méritos, parte das críticas anteriormente levantadas ao argumento coxiano original se aplicam a Robinson, pois este reproduz a ideia de "correia de transmissão". Ora, isso é problemático, pois alija do processo de constituição da globalização as próprias lutas de classe. Ou seja, há uma diferença fundamental entre perceber o processo de internacionalização/transnacionalização do Estado a partir de uma ênfase no processo de internalização dos interesses de classe no Estado, destacando aspectos de desnacionalização do Estado articulados aos processos de expansão transnacional das relações sociais, e a partir da metáfora da "correia de transmissão".

Falta em Robinson uma percepção sobre a dialética da territorialidade e da globalização. Sua tese de que a globalização, por ser uma mudança epocal, leva ao surgimento de um Estado transnacional ignora que o processo de estruturação das relações sociais do capitalismo deve ser entendido em associação com o "papel (cambiante) do Estado na reprodução social e espacial do capital" (LACHER, 2006, p. 12). Há uma contradição inerente, no processo de desenvolvimento das relações sociais capitalistas, entre os espaços de acumulação e os espaços de governança.

Além disso, segundo Robinson, "as condições materiais que deram origem ao Estado-nação [estariam] sendo superadas contemporaneamente pela globalização"; assim, "esta forma espacial particular de desenvolvimento desigual do capitalismo [estaria] sendo superada pela globalização do capital e dos mercados" (ROBINSON, 2004, p. 98-99). De acordo com Morton, tal afirmação expressaria a principal fraqueza de sua tese do Estado transnacional: a saber, a ideia de "homoeficiência do capitalismo" - suposição de que a difusão e o impacto do capitalismo ao redor do mundo se dariam de maneira uniforme, a despeito das "contradições do desenvolvimento desigual expresso 
através das relações variadas do capital nos distintos processos de formação estatal" (MORTON, 2007, p. 147). Contudo, conforme expresso pelo conceito de revolução passiva, as contradições do desenvolvimento desigual são expressão das lutas de classe que ocorrem através das diversas escalas espaciais, do âmbito local ao global, passando pelo estatal.

Isso fica claro quando as atenções são voltadas, por exemplo, para as crises econômicas que se acumulam principalmente a partir dos anos 1990 e para a resposta dada pelos países desenvolvidos a estas. Nesse contexto, duas respostas merecem destaque, ambas diretamente associadas à crise asiática (1997): primeiro, na resposta imediata dada pelos países desenvolvidos, ficou clara a ausência de consenso entre tais países acerca do modelo a ser adotado pelos países do sudeste asiático para sair da situação de crise. Houve uma clara oposição entre o modelo defendido pelos Estados Unidos e o modelo defendido pelo Japão, o que demonstra a impossibilidade de se pensar uma "homoeficiência do capitalismo", bem como o papel fundamental dos Estados enquanto atores nos processos de reconfiguração dos processos de acumulação em escala mundial e, neste caso, regional. Segundo, além de apontar para um desgaste do modelo neoliberal até então hegemônico, tal crise é fundamental, uma vez que, a partir dela, tem origem, no âmbito do G-7, aquilo que posteriormente ficaria conhecido como G-20. Tal política pode ser vista em um contexto de tentativa de restauração da legitimidade que vinha sendo perdida desde o eclodir das crises, ou seja, como um elemento dentro de um processo mais amplo de tentativa de revolução passiva em escala global, expressando assim as contradições do desenvolvimento desigual e como os Estados são incorporados em tais processos também de uma forma desigual (RAMOS, 2011).

Em suma, dizer que "os processos e as formações globais atuais podem, e logram, desestabilizar a hierarquia de escalas centradas no 
Estado nação" (SASSEN, 2007, p. 24) não significa dizer que novas escalas do nível global sobrepujem velhas escalas do nível nacional. Na verdade, o conceito de transnacionalização do Estado é fundamental para que se evite tanto a "cilada territorial" (AGNEW, 2005) quanto o globalismo: ambas as perspectivas padecem de uma ontologia rasa, já que negam o global ou o estatal como uma escala espacial ainda significativa no processo de acumulação do capital. Isso ajuda a iluminar o entendimento acerca dos processos de neoliberalização, que se por um lado se apresentam a partir de uma dimensão sistêmica (GILL, 2003), por outro têm se expressado historicamente a partir da reconstituição descontínua, desigual e contraditória das relações entre o global e nacional. Em outras palavras, os processos de neoliberalização têm, ao mesmo tempo, levado à expansão do neoliberalismo pelo mundo e intensificado "o desenvolvimento desigual das formas regulatórias através dos lugares, territórios e escalas", levando a uma "produção sistêmica de diferenciação geoinstitucional" (BRENNER et. al., 2010, p. 3).

Deve-se assim perceber como o processo de acumulação do capital ocorre através de relações sociais multiescalares, nas quais o Estado não é o ponto dominante, mas um ponto nodal. O espaço geográfico é "um conjunto indissociável de sistemas de objetos e sistemas de ações”, que variam conforme as épocas. Se é assim, então “os objetos que constituem o espaço geográfico atual são intencionalmente concebidos para o exercício de certas finalidades, intencionalmente fabricados e intencionalmente localizados. A ordem espacial resultante é, assim, intencional" (SANTOS, 2004, p. 332, ênfase nossa). Nesse sentido, é possível ver como a globalização, iniciada por influência dos Estados Unidos, gera uma transformação da ontologia espacial da política mundial, abrindo novas possibilidades escalares de articulação política e de acumulação do capital sem, contudo, negar a relevância das demais escalas (AGNEW, 2005). 


\section{Conclusão}

Percebe-se que, a partir de uma leitura neogramsciana que (i) vê a globalização como algo real sem, contudo, desconsiderar o papel do Estado nesse processo e (ii) que dá a devida importância para o papel desempenhado pelos Estados Unidos na origem e nos desdobramentos da configuração do poder global, é possível integrar dialeticamente tempo e espaço, incorporando, assim, "os aspectos contingentes, historicamente construídos da globalização, a agência dos atores e a diversidade dos processos contidos sob o pôster da globalização" (OKE, 2009, p. 323).

Assim, com a emergência da globalização, não há o fim ou a retirada do Estado, mas uma reestruturação das diferentes formas de Estado mediante a internalização, nos Estados, de "novas configurações de forças sociais expressas por uma luta de classes entre frações distintas (nacional e transnacional) do capital e do trabalho" (MORTON, 2007, p. 133). Através de uma perspectiva neogramsciana - mediante o conceito de transnacionalização do Estado -, é possível perceber como "o global pode [...] se constituir dentro do nacional" e como "o Estado tem na verdade ganhado poder porque tem que executar o trabalho de implementar as políticas necessárias para a economia corporativa global" (SASSEN, 2008, p. 63). Ou seja, tal conceito é fundamental no entendimento da economia política global contemporânea, pois contribui significativamente para a compreensão dos processos de desnacionalização (SASSEN, 2007).

Ao mesmo tempo em que apresenta uma profícua articulação entre o nacional e o internacional, dando importantes pistas para a reflexão sobre o global, Gramsci traz uma crítica ao estadocentrismo, não vendo o Estado como algo absoluto em um sentido fetichizado (GRAMSCI, 2002b, p. 279-280, Q8\$130; p. 332-333, Q15§13; 2002c, p. 349-351, Q1§150). Pelo contrário, este é visto como uma forma de relações sociais nas quais distinções metodológicas - e não 
orgânicas - podem ser feitas entre as dimensões relacionadas aos fenômenos do consenso e da coerção. Tal questão é pertinente porque abre espaço para se pensar as mudanças contemporâneas do Estado, ou seja, seu processo de desnacionalização, articuladas à emergência do global, e os impactos de tais questões na configuração da ordem e das dinâmicas de poder no âmbito mundial - como pode ser percebido a partir da análise da crise asiática (1997) e de seus desdobramentos, como a criação do G-20, por exemplo.

Em suma, é possível partir dos escritos de Gramsci para lidar com problemas semelhantes aos que lhe chamaram a atenção - como é o caso das contradições do capitalismo e os mecanismos de construção da hegemonia associados a este processo -, mas tendo a clareza de, quando necessário, fazer o movimento para além de Gramsci a fim de compreender os elementos constitutivos da economia política global contemporânea - como é o caso do conceito de transnacionalização do Estado que, embora tenha uma clara inspiração gramsciana, vai além de uma aplicação literal deste autor na medida em que busca lidar com os processos de reprodução ampliada do capital e seus desdobramentos no âmbito político em um contexto de intensificação da globalização. De todo modo, muito mais do que simplesmente aplicar os conceitos gramscianos de uma maneira mecânica e a-histórica, faz-se fundamental pensar o mundo de uma maneira gramsciana - ou seja, "a tarefa imediata é passar da abstração para a demonstração de como conceitos podem ter valor explanatório [...] através da confrontação da teoria com a prática" (MORTON, 2007, p. 38).

\section{Notas}

1. Duas questões merecem destaque neste ponto. Em primeiro lugar, é importante perceber que, neste período - em 1924, especificamente -, Gramsci desenvolveu pela primeira vez uma ideia que seria fundamental ao longo dos Cader- 


\section{Leonardo Ramos}

nos, a saber, a "diferença estrutural entre as formações econômico-sociais do 'Ocidente' e do 'Oriente', com a necessária consequência de que é preciso elaborar estratégias que levem em conta e se adéquem a essa diferença" (COUTINHO, 2007, p. 64). Em segundo lugar, tais evidências apontam para o fato de que não há, ao contrário do que afirma Joseph V. Femia (1981), uma distinção radical entre um "jovem" Gramsci pré-cárcere e um Gramsci "maduro", pós-cárcere. Como bem apontou Carlos Nelson Coutinho, embora o cárcere tenha aberto para Gramsci a possibilidade de uma reflexão distanciada dos eventos do cotidiano - gerando assim uma produção mais sistemática e universal -, "seria um erro, porém, pensar que essa produção carcerária nada tenha a ver com as vicissitudes históricas e políticas da época: o novo é que essa vinculação se dá agora num nível mais amplo, no nível do período histórico, e não naquele do dia a dia ou da conjuntura imediata" (COUTINHO, 2007, p. 81).

2. De acordo com Bruff (2009, p. 341-342), a ênfase dada pelos foucaultianos na natureza fluida e variada das relações de poder não passaria de uma tentativa de "mascarar austeridade epistemológica com a proclamação de uma modéstia epistemológica".

3. Para a relação entre tal conceito gramsciano e o conceito de "via prussiana" de Lenin, ver Coutinho (2007, p. 66).

4. Sobre a questão da causalidade e de seu entendimento nas Relações Internacionais, ver Kurki (2008).

5. Neste sentido, ver também Cox (1994, p. 65).

6. O trabalho de Mark Rupert acerca da relação entre americanismo, fordismo e hegemonia e o impacto da globalização neste processo é fundamental para uma melhor compreensão dessas questões. Neste sentido, ver, inter alia, Rupert (1995, 2000).

\section{Referências Bibliográficas}

AGNEW, John. Hegemony: the new shape of global power. Filadélfia: Temple University Press, 2005. 
BAKER, Andrew. Nébuleuse and the "internationalisation of the sate" in the UK? The case of HM Treasury and the Bank of England. Review of International Political Economy, v. 6, n. 1, p. 79-100, 1999.

BAKKER, Isabella; GILL, Stephen (Ed.). Production, power and social reproduction: human insecurity in the global political economy. Basingstoke: Palgrave, 2003.

BEDIRHANOGLU, Pinar. The state in neoliberal globalization: the merits and limits of Coxian conceptions. In: AYERS, A. (Ed.). Gramsci, political economy and international relations: modern princess and naked emperors. Basingstoke: Palgrave, 2008.

BIANCHI, Alvaro. Revolução passiva: o futuro do pretérito. Crítica Marxista, n. 23, p. 34-57, 2006.

BIELER, Andreas; MORTON, Adam D. The deficits of discourse in IPE: turning base metal into gold? International Studies Quarterly, v. 52, p. 103-128, 2008.

BRENNER, Neil; PECK, Jamie; THEODORE, Nik. Variegated neoliberalization: geographies, modalities, pathways. Global Networks, v. 10, n. 2, p. 1-41, 2010.

BRUFF, Ian. The totalisation of human social practice: open Marxists and capitalist social relations, Foucauldians and power relations. British Journal of Politics and International Relations, v. 11, p. 332-351, 2009.

BUCI-GLUCKSMANN, Christine. Sobre os problemas políticos da transição: classe operária e revolução passiva. In: FERRI, F. (Coord.). Política e história em Gramsci. Rio de Janeiro: Civilização Brasileira, 1978.

COUTINHO, Carlos Nelson. Gramsci. Porto Alegre: L\&PM, 1981.

Gramsci: um estudo sobre seu pensamento político. 3. ed. Rio de Janeiro: Civilização Brasileira, 2007.

COX, Robert W. Production, power and world order: social forces in the making of history. Nova Iorque: Columbia University Press, 1987.

Gramsci, hegemony and international relations: an essay in method. In: GILL, S. (Ed.) Gramsci, historical materialism and international relations. Cambridge: Cambridge University Press, 1994. 
. Social forces, states and world orders: beyond international relations theory. In: COX, R. W.; SINCLAIR, T. J. Approaches to world order. Cambridge: Cambridge University Press, 1996a.

Global perestroika. In: COX, R. W.; SINCLAIR, T. J. (Ed.). Approaches to world order. Cambridge: Cambridge University Press, $1996 \mathrm{~b}$.

The political economy of a plural world: critical reflections on power, morals and civilization. Londres: Routledge, 2002.

FEMIA, Joseph V. Gramsci’s political thought. Oxford: Clarendon, 1981.

Gramsci, Machiavelli and international relations. Political Quarterly, v. 76, n. 3, p. 341-349, 2005.

GERMAIN, Randall; KENNY, Michael. Engaging Gramsci: International Relations theory and the new Gramscians. Review of International Studies, v. 24, p. 3-21, 1998.

GILL, Stephen. American hegemony and the trilateral commission. Cambridge: Cambridge University Press, 1990.

Power and resistance in the new world order. Nova Iorque: Palgrave Macmillan, 2003.

; LAW, David. Global hegemony and the structural power of capital. International Studies Quarterly, v. 33, p. 475-499, 1989.

GRAMSCI, Antonio. A questão meridional. Rio de Janeiro: Paz e Terra, 1987.

_ Cadernos do cárcere. v. 4. Rio de Janeiro: Civilização Brasileira, 2001a.

_ Cadernos do cárcere. 2. ed. v. 2. Rio de Janeiro: Civilização Brasileira, 2001b.

__ Cadernos do cárcere. v. 5. Rio de Janeiro: Civilização Brasileira, 2002a.

_ Cadernos do cárcere. 3. ed. v. 3. Rio de Janeiro: Civilização Brasileira, 2002b.

__. Cadernos do cárcere. v. 6. Rio de Janeiro: Civilização Brasileira, 2002c.

_ Cadernos do cárcere. $3^{\mathrm{a}}$ ed. Rio de Janeiro: Civilização Brasileira, v. 1, 2004. 
Ordem e Poder na Economia Política Global: A Contribuição Neogramsciana ra, 2005.

Cartas do cárcere. v. 1: 1926-1930. Rio de Janeiro: Civilização Brasilei-

GRUPPI, Luciano. O conceito de hegemonia em Gramsci. 2. ed. Rio de Janeiro: Edições Graal, 1978.

JESSOP, Bob. Gramsci as a spatial theorist. Critical Review of International Social and Political Philosophy, v. 8, n. 4, p. 421-437, 2005.

KURKI, Milja. Causation in international relations: reclaiming causal analysis. Cambridge: Cambridge University Press, 2008.

LACHER, Hannes. Beyond globalization: Capitalism, territoriality and international relations of modernity. Nova Iorque: Routledge, 2006.

LIGUORI, Guido. Roteiros para Gramsci. Rio de Janeiro: UFRJ, 2007.

LING, L. H. M. Hegemony and the internationalizing state: a post-colonial analysis of China's integration into Asian corporatism. Review of International Political Economy, v. 3, n. 1, p. 1-26, 1996.

MELLO, Alex Fiúza de. Mundialização e política em Gramsci. São Paulo: Cortez, 1996.

MORTON, Adam David. Unravelling Gramsci: hegemony and passive revolution in the global political economy. Londres: Pluto, 2007.

OKE, Nicole. Globalizing time and space: temporal and spatial considerations in discourses of globalization. International Political Sociology, n. 3, p. 310-326, 2009.

PANITCH, Leo. Rethinking the role of the State. In: MITTELMAN, J. H. (Ed.). Globalization: critical reflections. Londres: Lynne Rienner Publishers, 1997.

PRZEWORSKI, Adam. Capitalismo e social-democracia. São Paulo: Companhia das Letras, 1989.

RAMOS, Leonardo César Souza. Hegemonia, revolução passiva e globalização: o sistema G7/8. Tese (Doutorado em Relações Internacionais) - PUC-Rio, Rio de Janeiro, 2011.

ROBINSON, William I. Promoting polyarchy: globalization, US intervention and hegemony. Cambridge: Cambridge University Press, 1996. 
. Social theory and globalization: the rise of a transnational State. Theory and Society, v. 30, n. 2, p. 157-200, 2001.

A theory of global capitalism: production, class, and State in a transnational world. Baltimore: Johns Hopkins University Press, 2004.

Global capitalism theory and the emergence of transnational elites. Working Paper 2010/02. Tóquio: United Nations University - World Institute for Development Economics Research, 2010. Disponível em: $<$ http://www.soc.ucsb.edu/faculty/robinson/Assets/pdf/WIDER.pdf $>$. Acesso em: 19 jul. 2010.

RUGGIE, John G. International regimes, transactions and change: embedded liberalism in the postwar economic order. International Organization, v. 2, n. 36, p. 379-415, 1982.

RUPERT, Mark. Alienation, capitalism and the inter-state system: toward a Marxian/Gramscian critique. In: GILL, S. (Ed.). Gramsci, historical materialism and international relations. Cambridge: Cambridge University Press, 1994.

Producing hegemony: the politics of mass production and American global power. Cambridge: Cambridge University Press, 1995.

Ideologies of globalization: contending visions of a new world order. Londres: Routledge, 2000.

Globalising common sense: a Marxian-Gramscian (re-)vision of the politics of governance/resistance. In: ARMSTRONG, D.; FARRELL, T.; MAIGUASHCA, B. (Ed.). Governance and resistance in world politics. Cambridge: Cambridge University Press, 2003.

SANTOS, Milton. A natureza do espaço: técnica e tempo, razão e emoção. São Paulo: Edusp, 2004.

SASSEN, Saskia. Una sociología de la globalización. Buenos Aires: Katz, 2007.

Neiher global nor national: novel assemblages of territory, authority and rights. Ethics \& Global Politics, v. 1, n. 1-2, p. 61-79, 2008.

SASSOON, Anne Showstack. Gramsci's politics. Nova Iorque: St. Martin's Press, 1980. 


\section{Ordem e Poder na Economia Política Global: A}

Contribuição Neogramsciana

SHILLIAM, Robbie. Hegemony and the unfashionable problematic of "primitive accumulation". Millennium: Journal of International Studies, v. 33, n. 1, p. 59-88, 2004.

VAN DER PIJL, Kees. Soviet socialism and passive revolution. In: GILL, S. (Ed.). Gramsci, historical materialism and international relations. Cambridge: Cambridge University Press, 1994.

Transnational classes and international relations. Londres: Routledge, 1998.

WORTH, Owen. The poverty and potential of Gramscian thought in international relations. International Politics, v. 45, p. 633-649, 2008.

\section{Resumo}

\section{Ordem e Poder na Economia Política Global: a Contribuição Neogramsciana}

O artigo busca apresentar as contribuições dadas por uma perspectiva neogramsciana para o entendimento das dinâmicas de ordem e poder na economia política global. Para tanto, divide-se em duas grandes partes: na primeira, será apresentado o pensamento de Gramsci em seu contexto para, em um segundo momento, ser desenvolvida uma releitura de Gramsci para além de seu contexto. Assim, tal releitura ocorrerá a partir do engajamento com alguns autores neogramscianos, como Robert W. Cox, Stephen Gill, William I. Robinson, Adam Morton e John Agnew. Neste processo, será feita uma discussão sobre a incorporação da obra de Gramsci na economia política global, com destaque para os impactos da globalização para a Pax America$n a$ e, consequentemente, para o processo de internacionalização/transnacionalização do Estado.

Palavras-chave: Gramsci - Internacionalização do Estado - Transnacionalização do Estado - Globalização - Hegemonia 


\section{Abstract}

\section{Order and Power in the Global Political Economy: The Neo-Gramscian Contribution}

The article aims to present the contribution of a neo-Gramscian perspective to the understanding of the dynamics of order and power in the global political economy. In this sense, it is divided in two parts: the first, it is presented Gramsci's thought in its context, in order to, in the second moment, develop a re-reading of Gramsci beyond its context. Hence, such re-reading will occur through an engagement with some neo-Gramscian scholars, such as Robert W. Cox, Stephen Gill, William I. Robinson, Adam Morton and John Agnew. In this process, it will be discussed the incorporation of Gramsci's work in Global Political Economy field, with special attention to the process of internationalization/transnationalization of the State.

Keywords: Gramsci - Internationalization of State - Transnationalization of State - Globalization - Hegemony 